\title{
Observed and modeled larval settlement of a reef fish to the Florida Keys
}

\author{
S. Sponaugle ${ }^{1, *}$, C. Paris $^{2}$, K. D. Walter ${ }^{1}$, V. Kourafalou ${ }^{3}$, E. D'Alessandro ${ }^{1}$ \\ ${ }^{1}$ Marine Biology and Fisheries, ${ }^{2}$ Applied Marine Physics, and ${ }^{3}$ Meteorology and Physical Oceanography, Rosenstiel \\ School of Marine and Atmospheric Science, University of Miami, 4600 Rickenbacker Causeway, Miami, Florida 33149, USA
}

\begin{abstract}
The bipartite life history of most marine organisms leads to complex patterns of replenishment in benthic populations. High variation in adult spawning, dynamic oceanographic currents, and often unknown larval behaviors create challenges in accurately predicting spatial and temporal patterns in the supply and settlement of pelagic larvae to nearshore juvenile habitats. Yet, understanding and predicting larval exchange underlies population dynamics, ecological interactions, and conservation practices. We compared observed patterns of larval settlement of the bicolor damselfish Stegastes partitus (Pomacentridae) along the Florida Keys, USA, to those obtained through model simulations using a high-resolution biophysical model parameterized with species-specific early life-history information. Light traps intercepted settlement-stage larvae, and divers censused new recruits at 2 replicate reefs in each of the upper (eastern) (UK) and lower (western) Keys (LK) during 6 peak settlement periods. Damselfish settlement and recruitment to the LK consistently exceeded that to the UK. Remarkably, model simulations successfully explained $70 \%$ of temporal variation in settlement within each region. However, the model did not capture the relative magnitude of observed settlement between the regions: settlement was either overestimated in the UK or underestimated in the LK. Potential causes include weak larval settlement cues or larval ability to navigate and swim to settlement habitat in the UK, higher larval condition and survival in the more productive waters of the LK, or substantial spatial variation in reproductive output. Connectivity matrices indicate that a majority of $S$. partitus settlement to the Florida Keys is sourced from Keys populations.
\end{abstract}

KEY WORDS: Larval dispersal - Recruitment - Population connectivity - Stegastes partitus · Biophysical model

Resale or republication not permitted without written consent of the publisher

\section{INTRODUCTION}

Most benthic marine organisms produce offspring that spend a portion of their development as pelagic larvae. Subjected to oceanographic currents and constraints on growth and survival, these larvae must eventually settle to a suitable habitat to complete their lifecycle. Understanding and predicting temporal and spatial patterns in larval settlement is notoriously challenging. Variation in adult spawning, larval growth, development, behavior, and survival, coupled with highly variable dynamic oceanography, challenges our ability to predict larval settlement.
Yet the influx of young into a population is an essential component of population dynamics, ecological interactions, and from an applied perspective, our ability to manage and conserve coastal populations (Cowen \& Sponaugle 2009).

Coral reef fishes are an important component of highly diverse coral reef ecosystems, and many previous efforts have quantified the dynamics of settlement and recruitment of young into the population for a variety of species (see Doherty 2002 for review). Larval distribution studies (Cowen \& Castro 1994, Limouzy-Paris et al. 1997, Paris \& Cowen 2004) and modeling efforts (Paris et al. 2002) have pointed to 
the role of physical transport processes and larval behavior in delivering reef fish larvae to nearshore settlement habitats. To more directly examine the physical and biological mechanisms associated with settlement, process-oriented studies have correlated relatively short time series of larval supply or settlement with particular climatological (Shenker et al. 1993, Milicich 1994, Thorrold et al. 1994, Kingsford \& Finn 1997, Lemberget et al. 2009, Lo-Yat et al. 2011) or physical oceanographic events (Cowen 2002, Sponaugle et al. 2005, D'Alessandro et al. 2007, Caselle et al. 2010). Others have related large pulses of settlement to larger hatch sizes of larvae (Macpherson \& Raventos 2005), faster larval growth (Bergenius et al. 2002, Jenkins \& King 2006, Sponaugle et al. 2006), larger larval size-at-settlement (Wilson \& Meekan 2002), or larvae of higher condition/ lower stress (Lemberget \& McCormick 2009). Similarly, spatial variation in patterns of fish settlement has been related to spatial variation in onshore flow or current speeds (Sponaugle \& Cowen 1996, Paris et al. 2002, Schmitt \& Holbrook 2002). Settlement time series are necessary for teasing apart causal mechanisms, because recruitment (measured when settling larvae have entered the benthic juvenile population) can obscure settlement patterns due to postsettlement processes (Shanks 2009). However, few efforts have been able to predict reliably patterns of settlement (for reef fishes or other marine organisms) over time and space, particularly in complex coastal environments.

Quantification of current and future changes in population-level and ecosystem-wide processes requires the development of sophisticated high-resolution biophysical models that can capture speciesspecific life-history characteristics on an individual basis as well as complex oceanography and environmental fluxes (Gallego et al. 2007, Werner et al. 2007). Such models have been and continue to be developed and expanded to quantify present (e.g. Cowen et al. 2000, 2006, Paris et al. 2005, 2007, Baums et al. 2006, Mitarai et al. 2008, North et al. 2008, Siegel et al. 2008, Watson et al. 2010) and future (O'Connor et al. 2007) levels of population exchange in marine organisms. However, there are very few published examples of direct comparisons between settlement obtained from such models and observed settlement patterns (see, however, Jenkins \& Black 1994, Brown et al. 2005).

In the context of a larger interdisciplinary study of population connectivity, we measured the replenishment of a common reef fish to the Florida Keys, USA, over space and time, as well as simulated this reple- nishment using a coupled high-resolution particletracking biophysical model. Our goals were to: (1) measure relative patterns of settlement between the upper and lower Florida Keys (separated by $100 \mathrm{~km}) ;(2)$ examine whether spatial patterns of settlement led to regional differences in recruitment; and (3) test whether simulations of a parameterized biophysical model could capture spatial and temporal variation in larval settlement. We also (4) used the model to estimate probabilities of population exchange (connectivity) within and beyond the Keys.

\section{MATERIALS AND METHODS}

\section{Settlement and recruitment measurements}

Many reef fish species, including Stegastes partitus (Pomancentridae), settle to reefs of the Florida Keys during the dark half of the lunar cycle encompassing the third quarter and new moons (D'Alessandro et al. 2007). Therefore, our nightly sampling for the present study was concentrated during the $15 \mathrm{~d}$ of peak settlement each lunar cycle. Six 15 d periods were sampled over June-September 2007 and 2008. Settlement periods sampled were: (1) June 5-18, 2007; (2) July 3-15, 2007; (3) August 1-14, 2007; (4) August 31-September 13, 2007; (5) June 21-July 6, 2008; and (6) July 23-August 4, 2008. To examine regional patterns in larval supply, we sampled 2 sites within each of the upper (eastern) (UK) and lower (western) Keys (LK; Fig. 1). Four replicate traps were deployed at each of Pickles and Sand Island reefs in the UK and American Shoal and Looe Key reefs in the LK. Due to their geographic separation, LK sites were sampled by a different team than the UK reefs; however, all other aspects of trap deployment and retrieval were identical.

Traps were modified from an earlier design by Sponaugle \& Cowen (1996) and consisted of a $\sim 1 \mathrm{~m}$ long, $0.5 \mathrm{~m}$ diameter cylinder of $500 \mu \mathrm{m}$ Nitex mesh netting (Bellamare) tapering to a removable plastic 11 cod-end. A $6 \mathrm{~W}$ fluorescent bulb powered by a $12 \mathrm{~V}$ battery (Bellamare) was inserted through the top of the trap to hang in the center of the mesh netting. Phototaxic larvae entered the trap via one of six $15 \mathrm{~cm}$ funnel openings and were collected in the codend during trap retrieval. Four replicate traps were attached to semi-permanent moorings > 200 m apart, positioned just seaward of the reef. Buoyant traps were weighted with lead weights to suspend vertically $\sim 1 \mathrm{~m}$ below the surface. Traps were deployed from a small boat at dusk and retrieved the following 


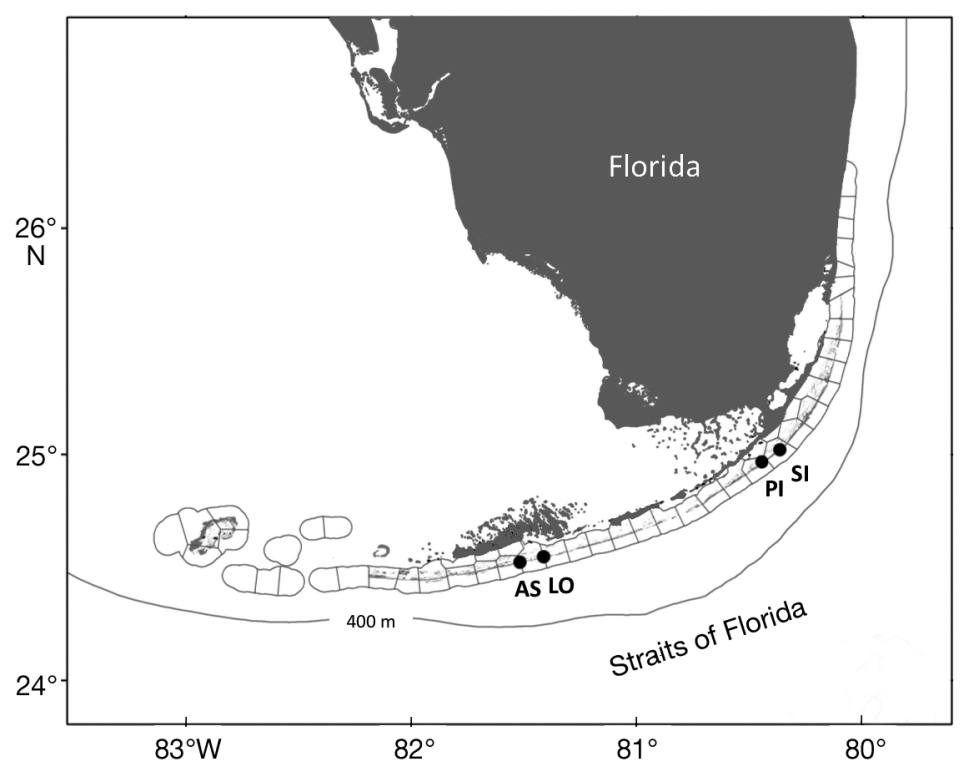

Fig. 1. Florida and the Florida Keys, USA (dark gray), offshore reefs (light gray), and study sites (•) at Pickles (PI) and Sand Island (SI) reefs in the upper Keys and American Shoal (AS) and Looe Key (LO) reefs in the lower Keys. Florida Keys habitat polygons used in the biophysical modeling are superimposed along with the $400 \mathrm{~m}$ isobath offshore interactions were present, 1-way ANOVAs or multiple comparisons as above.

\section{Modeling}

We used the connectivity modeling system (CMS), a coupled biophysical model developed by Paris et al. (2007), to simulate spawning, larval transport, and settlement in a seascape matrix-based framework. The latest version of the CMS has a unique multi-scale capability to acquire data through open-source project for a network data access protocol (OPeNDAP) from a hierarchy of nested ocean circulation models and thus maximize resolution of the currents during the larval tracking. This attribute was particularly critical in the present study to capture both the submesoscale circulation features of the Florida Keys together with the mesoscale circulation of the open ocean to track larvae hatching nearshore with a potential of dispersing offshore and then returning to the near-

morning after sunrise. Samples were removed and preserved in $95 \%$ ethanol for transportation to the field station. In the laboratory, samples were sorted for fish larvae that were identified to the lowest taxonomic level using region-specific guides (Richards 2005).

Following the appearance of late-stage larvae in light traps, teams of SCUBA divers surveyed the benthos for newly recruited juveniles. At each of the 4 sites, 15 haphazardly placed $5 \times 1 \mathrm{~m}$ transects were visually surveyed and sampled in each of the reef and surrounding sand/rubble habitats for Stegastes partitus recruits. Densities of $S$. partitus were higher on rubble substrates; thus, we focused recruitment analyses on these transects.

For the purposes of the present study, nightly larval settlement was computed as the mean larval Stegastes partitus abundance per trap of all replicates across the 2 sites in each region. We calculated mean settlement per region for each of the six $15 \mathrm{~d}$ sampling periods and compared these between regions and time periods using a 2-way ANOVA, followed by a 1-way ANOVA or multiple comparisons for each factor within the levels of the other factor when interactions were significant. Similarly, recruitment of $S$. partitus was computed as the mean density of new recruits across both sites in each region, and this was similarly analyzed using a 2-way ANOVA and, when shore to settle. We thus used a hierarchy of hydrodynamic models nested within each other, all based on the community code of the hybrid coordinate ocean model (HYCOM; http://hycom.org). The models start from the very high-resolution $\left(1 / 100^{\circ}\right.$, ca. $\left.900 \mathrm{~m}\right)$ Florida Straits, South Florida, and Keys model (FKeyS-HYCOM), nested within the data assimilative regional Gulf of Mexico model (GoM-HYCOM, resolution of $1 / 25^{\circ}$, ca. $3.7 \mathrm{~km}$ ), and finally the data assimilative Global-HYCOM model (resolution of $1 / 12^{\circ}$, ca. $7 \mathrm{~km}$ ). The FKeyS-HYCOM (Kang et al. 2008 , Kourafalou \& Kang in press) is bounded by latitude 22.8 to $26.1^{\circ} \mathrm{N}$ and longitude 79 to $83.4^{\circ} \mathrm{W}$, and employs detailed topography from the $2 \mathrm{~min}$ NRL DBDB2 global dataset of the Naval Research Lab, with additional corrections around the Florida Keys. The atmospheric forcing (3 hourly wind stress, air temperature, atmospheric humidity, heat fluxes, and precipitation) is provided by the coupled ocean/ atmospheric mesoscale prediction system (COAMPS; Hodur 1997, Hodur et al. 2002) at $27 \mathrm{~km}$ resolution. Daily HYCOM Global and 6 hourly FKeyS-HYCOM archives for 2007 and 2008 were used for the coupled simulations.

The seascape module of the CMS was created in ArcMap ${ }^{\circledR}$ by overlaying the coral reef millennium mapping dataset (Andréfouët et al. 2006) on the model domain with a $5 \mathrm{~km}$ buffer (sensory zone) and 
segmented using a $10 \mathrm{~km}$ tension, generating 50 unit polygons of $\sim 10 \mathrm{~km} \times 10 \mathrm{~km}$ along the Florida Keys (Fig. 1). In addition, we created polygons in potential upstream locations: 28 along the Caribbean Mexican coast, 31 for NW and SW Cuba, and 13 for the western Bahamas, including Cay Sal Bank located just across the Florida Straits. These polygons determined the spatial resolution of the matrix for both spawning production and larval supply patterns and were input into the CMS seascape module as $(X, Y$, $Z$ ), where $X$ and $Y$ were the coordinates of the vertices, and $Z$ the polygon number.

We parameterized the biological module of the CMS with the early life-history traits of Stegastes partitus collected during previous studies in the Florida Keys (Rankin 2010) and their ontogentic vertical migrating behavior revealed from repeated plankton surveys throughout their entire pelagic duration (Paris \& Cowen 2004). The observed larval vertical distribution patterns were statistically described by a vertical matrix $(z, t)$ of probability density distributions in the water column (z) through time $(t)$ with stage-specific center of mass and vertical spread. The model was seeded with particles in the surface layer, simulating the hatching of $S$. partitus eggs from the shallow reefs. After the first time-step, the model assimilated the observations by moving individual particles stochastically in the vertical following the vertical matrix. To describe the observed decreasing mortality rate with $S$. partitus pelagic duration (Paris 2009) we applied a decay rate $\lambda$ :

$$
N_{t+1}=N_{t} \times \mathrm{e}^{-\lambda t}
$$

where $N_{t+1}$ is the number of larvae surviving at time $(t+1)$ and $\lambda$ the decay constant computed as:

$$
\lambda=\ln (2) /(\mathrm{PLD} / 2)
$$

where PLD is the pelagic larval duration (or the maximum competency period).

The timing of successful spawning was back-calculated from otoliths (ear stones) of late-stage larvae collected from the Florida Keys during 2000-2004. Calendar dates were converted to days of a lunar month, with Day 1 as the new moon (Fig. 2A). The distribution of pelagic larval durations was similarly obtained through otolith microstructure data (Fig. 2B). Particles (larvae) were released daily from all locations according to the lunar-cyclic pattern of spawning measured from successful settlers, and a total of 10400 particles per polygon were released monthly from the new moon of April to the new moon of September in 2007 and 2008 (i.e. over 6 million particles were tracked from local Keys sources, and
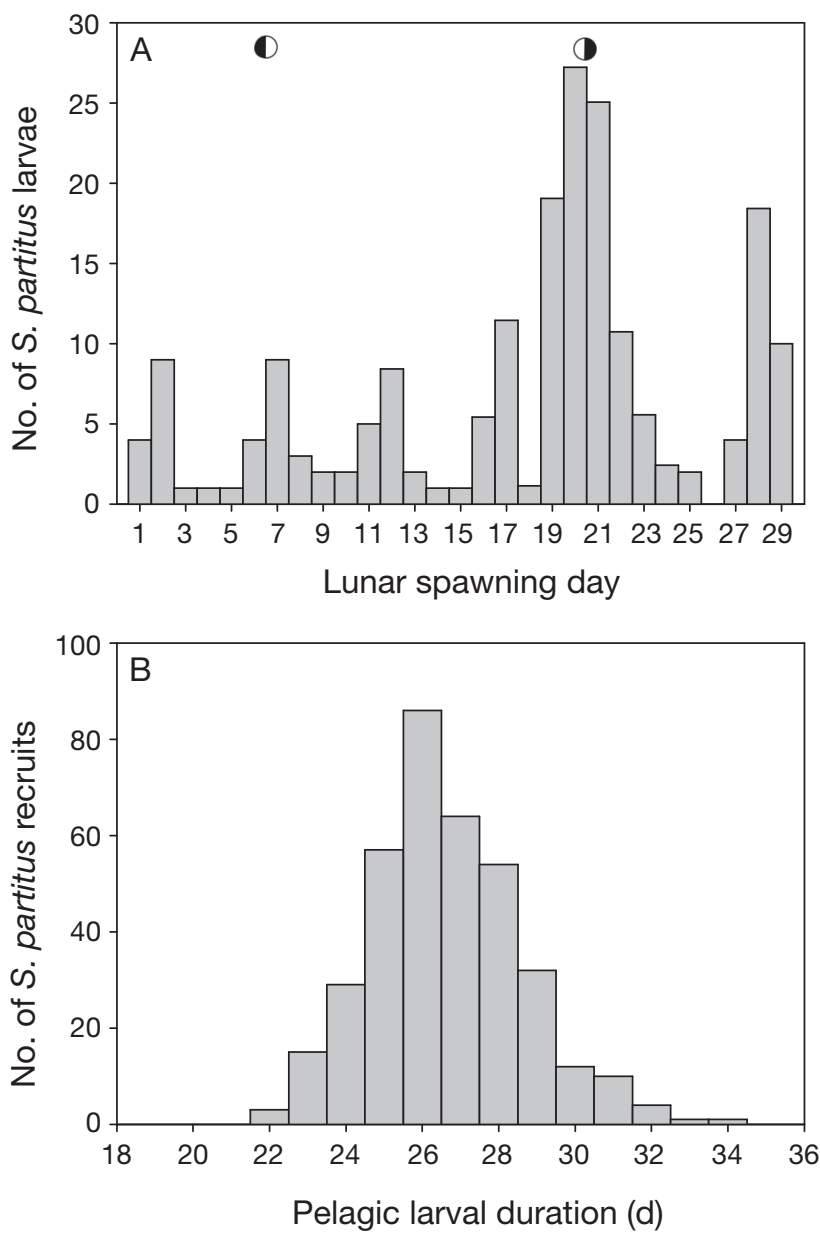

Fig. 2. Stegastes partitus. Early life-history data included in biophysical model. Distribution of (A) backcalculated lunarcyclic spawning from light trap larvae collected in the upper Florida Keys between May 2003 and January 2004 (Day 1 is new moon) and (B) pelagic larval duration of recruits to the upper Florida Keys from April 2003 to August 2008 (Rankin 2010)

over 9 million were tracked from upstream locations for this study). Transport was simulated until each particle became 'competent' to settle, after 22 to $32 \mathrm{~d}$ in the plankton. Settlement occurred when larvae entered the reef habitat polygons during this time period.

Even when data-assimilated, most realistic physical oceanographic models cannot perfectly couple time and space (Werner et al. 2007). Thus, we carried out both spatial and temporal smoothing in the raw modeled settlement data. First, for each day of the study period, the numbers of particles 'settling' to 6 polygons that encompassed the 2 sampling sites in each region (Fig. 1) were tabulated and summed. Second, we computed a $10 \mathrm{~d}$ running average on the time series of modeled daily settlement, allowing for some variance in the timing of the arrival. For each $15 \mathrm{~d}$ pe- 
riod of sampling, modeled settlement was compared to the observed supply of Stegastes partitus for each region (UK and LK). We also calculated the mean observed larval $S$. partitus supply over each $15 \mathrm{~d}$ period and regressed these against the mean modeled supply over the same periods for each region.

The model matrix output $\left(\boldsymbol{S}_{T}\right)$, where each cell $S_{T, i j}$ contains the number of surviving larvae from a source polygon $i$ settling to arrival polygon $j$, from the spawning period $T$, served as a means of investigating the probability of larval subsidies from outside the Florida Keys and the variability in larval linkages in the Florida Keys. We quantified the spatio-temporal patterns of foreign and locally spawned Stegastes partitus larvae by generating monthly connectivity probability matrices $\left(\boldsymbol{M}_{\boldsymbol{T}}\right)$ computed by normalizing the matrix output $\left(\boldsymbol{S}_{T}\right)$ by total settlement (and indirectly by production) as:

$$
\boldsymbol{M}_{T, i j}=\boldsymbol{S}_{T, i j} / \sum_{i} \boldsymbol{S}_{T, i j}
$$

The connectivity probability matrix $\boldsymbol{M}_{\boldsymbol{T}}$ represents the probability that an individual larva in polygon $i$ will migrate to polygon $j$. These matrices do not reflect the relative magnitude of settlement among locations from all possible spawning locations, but instead the probability that a larva spawned in one specific location arrived to settle at another location. The expected larval flux $F_{i j}$ from location $i$ to location $j$ depends on the magnitude of production $\left(P_{T, i}\right)$ :

$$
F_{T, i j}=P_{T, i} / \sum_{i} P_{T, i} \times \boldsymbol{M}_{T, i j}
$$

where $\sum_{i} P_{T, i}$ is the total monthly production (total number of particles released for a given lunar cyclic period $T$ in the model). Without information on spawning production and the size of the population, larval fluxes cannot be realistically quantified. Yet, we can accurately quantify $\boldsymbol{M}_{\boldsymbol{T}}$.

\section{RESULTS}

A total of 9489 late-stage Stegastes partitus larvae were collected during 65 nights of sampling 16 traps per night (plus an extra night in the LK), for a mean catch of 9 fish per trap. However, the majority of the larvae (8866) were collected from the LK (vs. 623 from the UK). Thus, in the LK, each trap collected a mean of 17 larvae each night, while UK traps collected a mean of 1 larva per trap per night. This pattern of higher settlement in the LK was evident across all 6 sampling periods (Fig. 3A), and significant in 5 of the 6 periods (2-way ANOVA: location, sampling period, and interaction all $\mathrm{p}<0.001$; 1-way
ANOVA [location within sampling period]: Period 1: $\mathrm{p}=0.058$; all other sampling periods: $\mathrm{p}<0.001-$ 0.028).

Regional patterns of recruitment echoed patterns of settlement: recruitment of Stegastes partitus was always higher to the LK than the UK, significantly so for 3 of the 6 periods (2-way ANOVA: location, sampling period, and interaction all $\mathrm{p}<0.001$; 1 -way ANOVA [location within sampling period]: Periods 1, 4, 5: $\mathrm{p}=0.134-0.390$; Periods 2, 3, 6: $\mathrm{p}<0.001$; Fig. 3B). The relationship between settlement $(S)$ and recruitment $(R)$ appeared to vary by region (UK: $\mathrm{r}^{2}=$ $0.47 ; \mathrm{p}=0.133 ; \mathrm{LK}: \mathrm{r}^{2}=0.83, \mathrm{p}=0.011$ ). However, because the range of settlement experienced by each region differed substantially (only overlapping at one point), the relationship between settlement and recruitment may be more parsimoniously viewed as a single nonlinear relationship $\left(R=0.2011 \times S^{0.4953} ; \mathrm{r}^{2}=\right.$ 0.87; $\mathrm{p}<0.0001$; Fig. 4). While a small change in settlement appeared to have a greater influence on

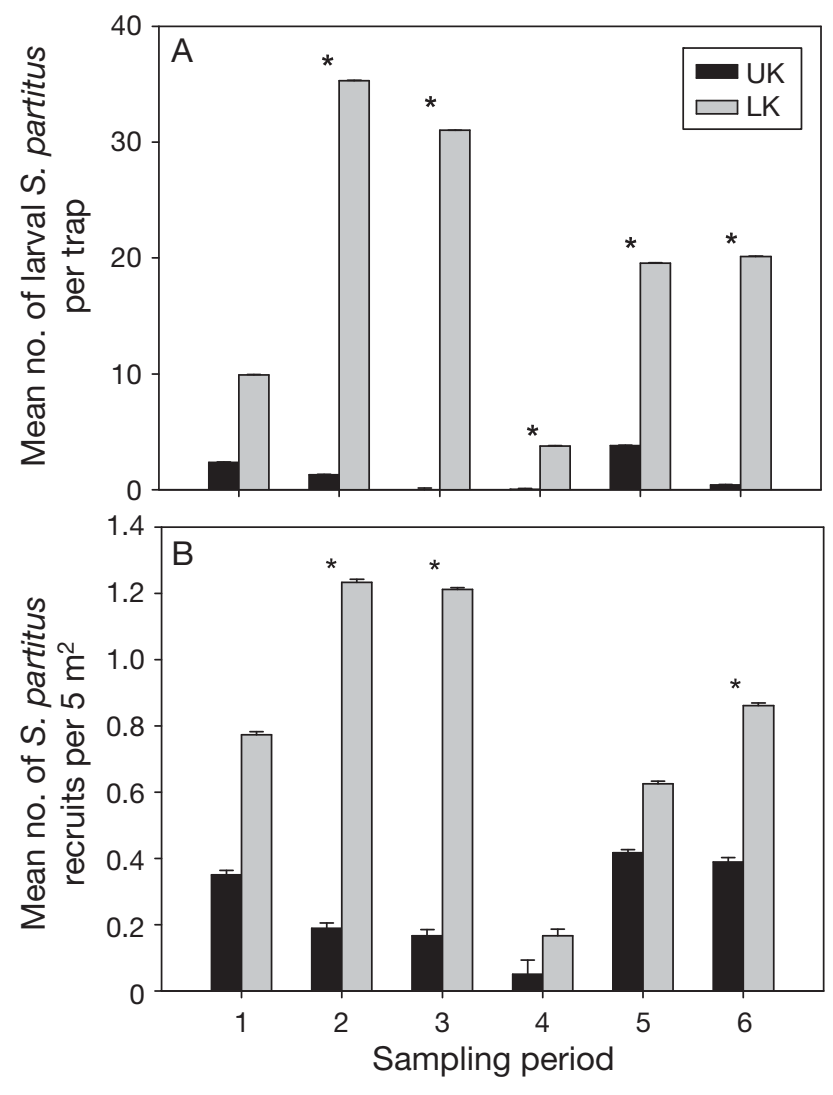

Fig. 3. Stegastes partitus. Mean $( \pm \mathrm{SE})(\mathrm{A})$ larval settlement (abundance per trap) and (B) recruitment to the upper (UK) and lower (LK) Florida Keys. Settlement measured by deployment of light traps over six 15 d sampling periods; recruitment (recruit density) quantified immediately after settlement by visual census of new recruits on coral rubble substrates. * Significant difference between UK and LK 
recruitment in the UK than in the LK, this could merely be because of the low and narrow range of settlement to that region.

Within each region, there was remarkable agreement between the relative magnitude of modeled and observed settlement between sampling periods (Figs. 5 \& 6). Essentially, the highest observed settlement within a region occurred during the period when the model predicted the highest settlement (i.e. Period 5 in the UK; Period 2 in the LK). Variation in modeled settlement explained $70 \%$ of the observed variation in settlement in each of the UK and LK (Fig. 6). However, on a regional basis, when modeled settlement was scaled to observed settlement in the LK, the model overestimated the magnitude of settlement to the UK (Fig. 5). Alternatively, when modeled settlement was scaled to the UK, modeled settlement was underestimated in the LK. While within region patterns were well explained by the model, betweenregion differences were not sufficiently captured. There was a greater spread in the range of settlement magnitude to each region than the model predicted. Fewer Stegastes partitus larvae settled to the UK, or more larvae settled to the LK, than expected.

The model's robustness in modeling settlement within regions allowed us to compute connectivity matrices to estimate the probability of larval dispersal among regions. Note that the mismatch in magnitude of modeled and observed larval supply between regions (as detailed in the paragraph above) may reflect spatially variable spawning production (see 'Discussion'), and such variation could affect the flux of

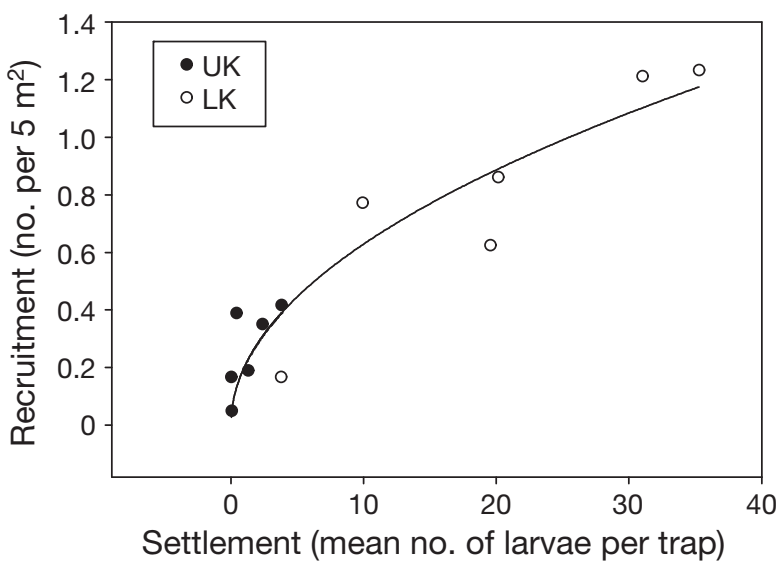

Fig. 4. Stegastes partitus. Relationship between observed settlement $(S)$ and recruitment $(R)$ to the upper (UK) and lower (LK) Florida Keys combined $\left(R=0.2011 \times S^{0.4953} ; \mathrm{r}^{2}=\right.$ 0.87 ; $<0.0001)$. Larval settlement measured as the mean number of $S$. partitus per light trap over each of six $15 \mathrm{~d}$ periods. Recruitment measured as the mean density of new recruits transect visually surveyed in coral rubble immediately following settlement pulses

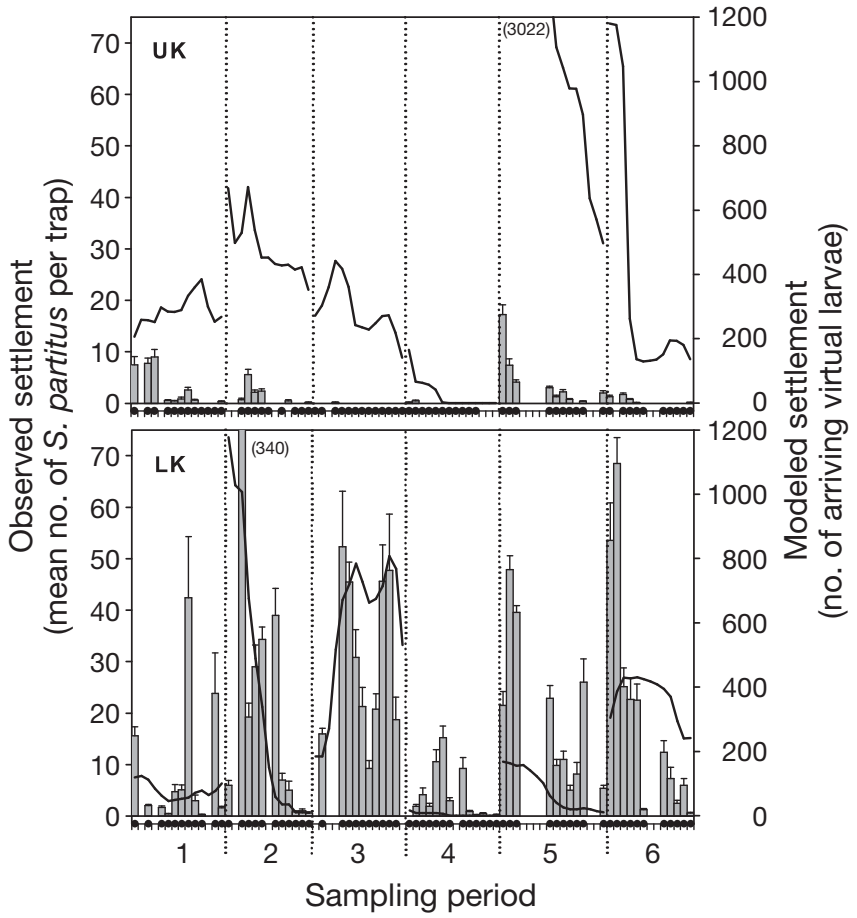

Fig. 5. Stegastes partitus. Observed (bars) and predicted (line) settlement of damselfish to the upper (UK) and lower (LK) Florida Keys. Late-stage larvae were collected during settlement by 4 replicate light traps deployed immediately offshore of reefs at each of 4 sites (the mean of both sites in each region is plotted). Light traps were deployed for $15 \mathrm{~d}$ during the peak settlement period encompassing the third quarter and new moons during each of 6 lunar cycles (2007: 4 cycles; 2008: 2 cycles), except where inclement weather prevented sampling. $(\bullet)$ Sampling nights. Lines: $10 \mathrm{~d}$ running average of predicted larval settlement to 6 polygons surrounding the 2 sampling sites in each of the Keys (UK and LK) from biophysical model runs. Note that overall magnitude of right $y$-axis for predicted data is arbitrary and based on the total number of particles released (10 400 particles per polygon released monthly); the important outcome is the relative pattern. Values in parentheses are those that extend beyond the plot. Error bars are $\pm \mathrm{SD}$

larvae migrating between locations $\left(F_{T}\right)$, but not the probability of larval linkages $\left(\boldsymbol{M}_{T}\right)$, which is normalized by the realized production, i.e. settlement. The connectivity probability matrices indicate that overall, both UK and LK regions likely received a majority of larvae from Florida Keys sources (Fig. 7). In August 2007, the probability of larval subsidies from the Bahamas to the western Keys was relatively high. Although these may have contributed to overall settlement to that locality that month, these subsidies were less frequent than those from the Yucatan Peninsula and Cuba that appear to constitute a steady, but low background level of recruitment to the Florida Keys. Larval connectivity was much stronger among Florida Keys locations. Within the Keys, as expected, there 


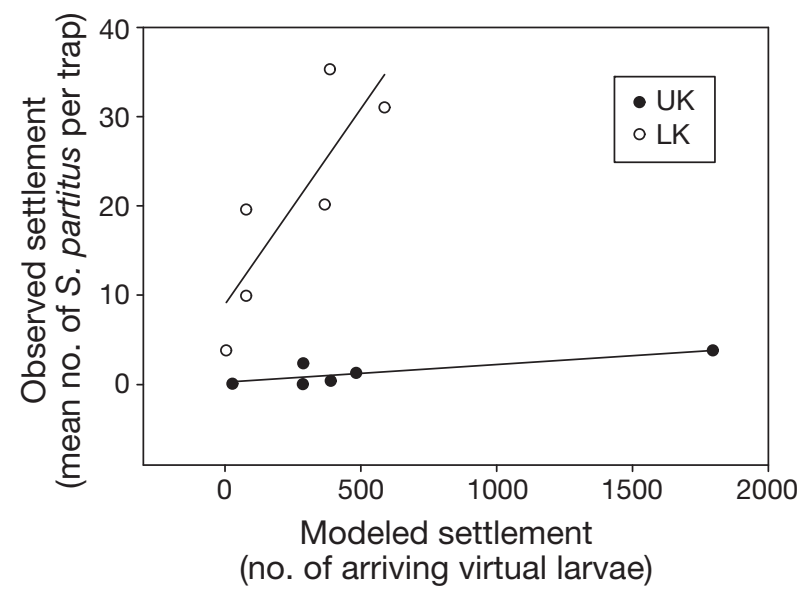

Fig. 6. Stegastes partitus. Linear regression of mean observed settlement vs. $10 \mathrm{~d}$ running average of settlement predicted from the biophysical model. Values computed for each of the six $15 \mathrm{~d}$ sampling periods in each region (upper Florida Keys, UK; lower Florida Keys, LK). Model-predicted settlement accounted for $70 \%$ of within-region variation in settlement (UK: $\mathrm{r}^{2}=0.70 ; \mathrm{p}<0.038 ; \mathrm{LK}: \mathrm{r}^{2}=0.70 ; \mathrm{p}<0.036$ ), but overall shape of regression differed between the UK and LK. Despite large variation in predicted settlement, very little variation in the magnitude of observed settlement to the UK leads to almost undetectable relationship

was a strong downstream signal each month whereby larvae spawned at upstream locations settled to downstream sites (evident in high levels of probable connectivity or the red-orange color below the selfsettlement diagonal in Fig. 7). Downstream settlement is expected in the Keys because of the dominant Florida Current flowing close to and along the Keys. However, re-circulating features and countercurrent flows enable upstream settlement as well, whereby larvae from downstream sites settle to upstream locations (evident in high levels of connectivity above the self-settlement diagonal). There was some probability of upstream settlement in most months, but this was especially substantial in June 2007 and August-September 2008 (Fig. 7). The probability of self-settlement (settlement of larvae to a region from which they were spawned) within the Keys varied by month and region: self-settlement to the UK was highest in July 2007 and July-August 2008, while probable selfsettlement to the LK was highest in June 2007 and August 2008.

\section{DISCUSSION}

To our knowledge, this is the first demonstration of a significant agreement between modeled and observed settlement of a coral reef fish. Our results help validate the use of such high-resolution bio- physical dispersal models and encourage their continual refinement. The model we used was parameterized with species-specific life-history data such as spawning periodicity, larval ontogenetic vertical migration, a mortality rate, observed PLD range, and a basic settlement behavior. The model did not include spatial variation in reproductive output, variation in larval growth, condition, or mortality, or any variation in settlement behavior. Despite these constraints, variation in modeled settlement magnitude explained $70 \%$ of variation in observed settlement within each region. Continual refinement of such models has great potential for quantifying current and future connectivity among local populations of marine organisms under different scenarios of environmental change.

\section{Within-region settlement patterns}

Within each of 2 regions of the Florida Keys, modeled estimates of larval settlement during six $15 \mathrm{~d}$ periods explained $70 \%$ of the variation in measured settlement. The biological parameters included in the model were essential to making the model realistic, but these parameters did not vary among periods. The temporal signal of the modeled settlement was generated by spawning (releasing) simulated larvae daily on a lunar cyclic schedule, mimicking observed spawning of successful settlers, and providing larvae with a PLD range also observed in new recruits (Rankin 2010). These 2 life-history processes were sufficient to roughly synchronize modeled settlement with the peak settlement measured on the reefs, but these parameters were consistent among periods. Spatially uniform mortality rate and larval vertical migration behavior were similarly constant among periods. Thus, fluctuations among study periods in the magnitude of settlement to each region were largely due to variation in oceanographic transport processes.

That oceanography should so closely predict within-region patterns of settlement points to the high-resolution and high-frequency forcing of the FKeyS-HYCOM upon which the biophysical model is built. The realism of the Florida Current variability is largely controlled by the boundary conditions through the nesting to the regional GoM-HYCOM model (attributes as in Kourafalou et al. 2009). The additional hydrodynamic details allowed by the resolution, topography, and forcing within the FKeySHYCOM are particularly important for the evolution of the mesoscale and sub-mesoscale eddy fields (Kourafalou \& Kang in press), which have been 


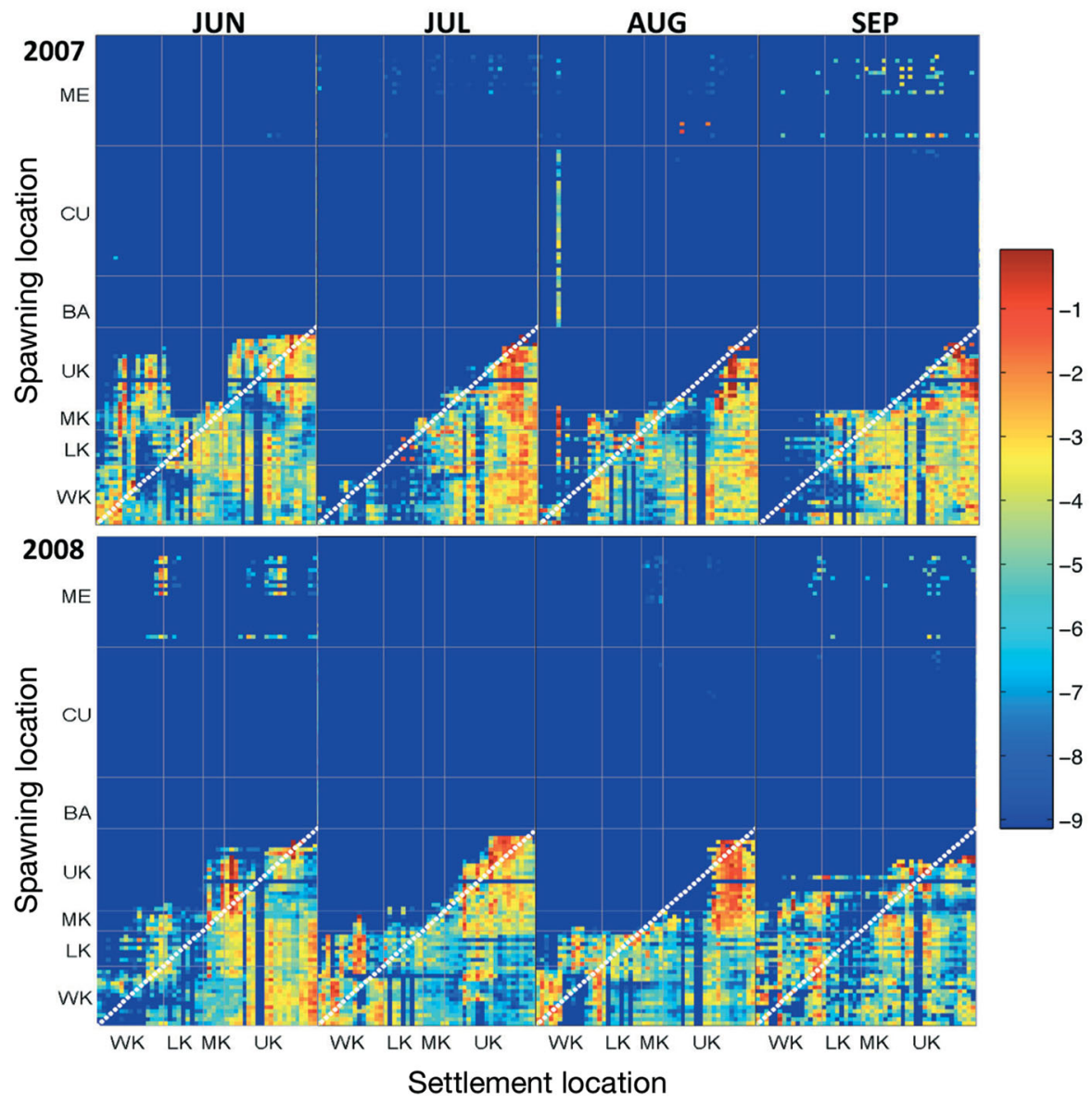

Fig. 7. Stegastes partitus. Connectivity probability matrices of predicted linkages within the Florida Keys (UK: upper Keys; MK: middle Keys; LK: lower Keys; and WK: western Keys) based on biophysical model outcome of releasing particles (larvae) from the reefs of the Florida Keys, Mexican Yucatan (ME), Cuba (CU), and the Bahamas (BA). The colorbar $\left(\log _{10}\right.$ scale: $0=100 \%,-1=10 \%$ probability, etc.) indicates the probability that larvae released from sites along the $y$-axis settle to sites along the $x$-axis. Note that in this situation, modeled connectivity is indicated for whole months, i.e. over more than the $15 \mathrm{~d}$ sampling periods each month. Self-settlement within the Keys is indicated where reddish colors (high probability of connectivity) track the white diagonal line. Reddish colors below diagonal line indicate downstream settlement; reddish colors above line indicate upstream settlement

shown to influence nearshore larval fish distributions (Limouzy-Paris et al. 1997, Richardson et al. 2009) and delivery to settlement habitats (Sponaugle et al. 2005, D'Alessandro et al. 2007).

\section{Between-region settlement patterns}

Despite the high concordance between the model and observed settlement within each region, the model consistently either overestimated settlement in the UK or underestimated settlement in the LK. When modeled settlement was scaled to observed settlement in the LK, observed settlement in the UK was substantially lower than modeled settlement. Other processes not included in the model may account for the lower than expected observed settlement in the UK.

\section{Larval depletion with progression along the Keys}

If larvae settle to the first available suitable habitat, settlement may be higher to the LK because these habitats would be encountered first by larvae transported in the Florida Current, which flows east to northeastward to eventually northward, roughly paralleling the Florida Keys. In addition, re-circulating mesoscale eddies have higher residency times in the LK, providing additional opportunities for larvae to settle. However, the model incorporates standard larval settlement criteria whereby settlement occurs if a larva is within $5 \mathrm{~km}$ of a suitable site within the 22 to $32 \mathrm{~d}$ PLD timeframe. Thus, the model theoretically should capture larval depletion, unless larval condition (addressed in the subsection below) or settlement criteria change with distance along the Keys.

\section{Variation in larval behavior}

Little is known regarding the ability of larvae to detect and navigate to suitable settlement habitat in the Florida Keys. Recent behavioral studies with late-stage Stegastes partitus larvae released at and tracked from offshore locations in the UK demonstrated the importance of directed swimming; however, larval swimming trajectories were not oriented 
in a particular direction (Huebert \& Sponaugle 2009). Elsewhere, larvae of other pomacentrids have been shown to orient either to or from island reefs depending on local conditions (reviewed in Leis 2006). Navigation to settlement habitats may be facilitated by larval response to reef sounds (Tolimieri et al. 2004, Simpson et al. 2005), or scents (Atema et al. 2002, Kingsford et al. 2002, Gerlach et al. 2007), and at closer ranges, the presence of conspecifics (Sweatman 1988). Depending on the specific mechanisms used by $S$. partitus to reach settlement habitats in the Florida Keys, either the behavioral cues emanating from nearshore sites or the ability of larvae to reach the suitable habitat may change along the Keys. For example, there are more extensive shallow backreef, seagrass, and mangrove habitats in the LK (Lidz et al. 2006) that may provide a stronger settlement signal. It is also possible that larvae have greater difficulty orienting and swimming out of the strong Florida Current to suitable settlement sites in the UK, or that they encounter a different suite of offshore predators during settlement in the UK than in the LK (e.g. see D'Alessandro \& Sponaugle 2011).

Alternatively, we can view the situation between the 2 regions of the Florida Keys from the reverse perspective: if modeled settlement is instead scaled to observed settlement in the UK, observed settlement to the LK greatly exceeded modeled settlement for all 6 sampling periods. As mentioned previously, mesoscale eddies form upstream and propagate along the Florida Current boundary, producing major current re-circulations that typically have a long residency in the LK. These same mesoscale features eventually propagate to the UK, but as they are increasingly constrained by a narrow bathymetry, they move more rapidly and begin to shear apart in the UK (Lee et al. 1994). The potential additional contributions of these mesoscale eddies to larval settlement in the LK are captured in the model, so larval transport by these features cannot account for this additional unexplained settlement. However, recirculation of these cyclonic eddies induces upwelling, bringing nutrients into the photic zone and enhancing water column productivity (Hitchcock et al. 2005). Cascading trophic food webs may lead to enhanced larval fish condition in the LK and potentially enhanced larval survival in the plankton to the point of settlement. Spatial and temporal differences in larval growth, condition, and survival are not parameterized in the model at this time and may underlie the enhanced settlement observed in the LK.

\section{Connectivity patterns}

The close match within regions of observed and modeled settlement lends confidence in the use of the biophysical model to examine the connectivity between several upstream and downstream spawning locations and within each region of the Florida Keys. We analyzed region-specific probability matrices for each sampling period to examine the degree to which connectivity changed temporally. Modeled settlement to the Keys indicated a very low probability of subsidy from non-Keys sources. Except for July 2008, when there was no upstream subsidy, generally there was a low level of settlement from only a few non-Keys sources, representing a steady but very low-level background of subsidy. Although not substantial, such long distance connectivity (assuming recruit survival) is likely sufficient to homogenize genetic signatures among local populations of Stegastes partitus (Purcell et al. 2009).

Importantly, during our modeling exercise we released a constant number of particles from each spawning source. In reality, there is likely much variation in population densities, access to food, and, consequently, reproductive output from different source populations. Adult Stegastes partitus on forereefs in the lower Keys have higher growth rates, asymptotic sizes, and fecundity than those in back reef habitats (Figueira et al. 2008). Food supplementation increased female growth (future reproductive output) and larval energy reserves (oil globule) on natural reefs in the Bahamas (Samhouri 2009). Particular areas along the Keys that receive higher zooplankton flux or have other characteristics that enhance growth and reproduction of $S$. partitus may have a disproportionate effect on larval settlement, and potentially, connectivity.

The degree to which this occurs and the impact of such variation on realized connectivity is unknown. Sensitivity analyses of variation in reproductive output are beyond the scope of the present study, and quantification of natural variation in such parameters is a substantial, though potentially important, undertaking. However, barring significant differences in the reproductive output between non-Keys and Keys sources, our results illustrate that there is only rather limited temporal variability in connectivity among distant locations, with the majority of Stegastes partitus settlement to the Keys consisting of larvae from Keys populations.

The degree to which within-Keys regions are primarily self-settled varies by month and location. This is not surprising given that the region is very dyna- 
mic, with strong interactions between the frontal boundary of the meandering Florida Current and the wide Florida shelf and inshore reef system. Mesoscale and small-scale eddies dominate the circulation, generating current reversals and westward flow as they translate northward. These transient oceanographic features have been shown to be important for larval retention and exchange (Limouzy-Paris et al. 1997, Sponaugle et al. 2005). However, biophysical modeling and connectivity matrices integrate these processes and can be computed over varying temporal periods. Our results suggest that dominant oceanographic features lend some continuity to connectivity matrices constructed over relatively short time periods, but that these also capture short-term variations in oceanography. Further parameterization of the model with ecological variables such as variation in reproductive output has the potential to add further variation to connectivity matrices, but the relative contribution of this variation in the context of a dominant oceanographic field is yet unknown.

Acknowledgements. This study was supported through a grant from the National Science Foundation (OCE 0550732) to S.S., R. K. Cowen, C.P., V.K., and T. Lee. Light trap construction provided by C. Guigand and Bellamare LLC. Light trap deployment was made possible with help from K. Shulzitski, T. Rankin, K. Huebert, S. Bignami, L. Havel, J. Boulay, S. Wilhelm, L. Jones, and T. Murphy. Sample sorting involved many of the above individuals as well as J. Robbins, J. Silverman, C. Gioia, C. Clark, S. Mui, A. Hogarth, and C. Hill. T. Rankin provided Stegastes partitus early lifehistory data for model parameterization. Assistance with biophysical modeling provided by J. Helgers supported by NSF-OCE 1048607 and with HYCOM modeling provided by H. Kang. R. K. Cowen provided comments on an earlier version. Any opinions, findings, conclusions, or recommendations expressed in this material are those of the authors and do not necessarily reflect the views of the National Science Foundation.

\section{LITERATURE CITED}

Andréfouët S, Muller-Karger FE, Robinson JA, Kranenburg CJ, Torres-Pullizza D, Spraggins SA, Murch B (2006) Global assessment of modern coral reef extent and diversity for regional science and management applications: a view from space. In: Suzuki Y, Nakamori T, Hidaka M, Kayanne $\mathrm{H}$ and others (eds) Proceedings of 10th International Coral Reef Symposium. Japanese Coral Reef Society, Okinawa, p 1732-1745

Atema J, Kingsford MJ, Gerlach G (2002) Larval reef fish could use odour for detection, retention and orientation to reefs. Mar Ecol Prog Ser 241:151-160

Baums I, Paris CB, Chérubin LM (2006) A bio-oceanographic filter to larval dispersal in a reef building coral. Limnol Oceanogr 51:1969-1989

Bergenius MAJ, Meekan MG, Robertson DR, McCormick
MI (2002) Larval growth predicts the recruitment success of a coral reef fish. Oecologia 131:521-525

Brown CA, Jackson GA, Holt SA, Holt GJ (2005) Spatial and temporal patterns in modeled particle transport to estuarine habitat with comparisons to larval fish settlement patterns. Estuar Coast Shelf Sci 64:33-46

Caselle JE, Kinlan BP, Warner RR (2010) Temporal and spatial scales of influence on nearshore fish settlement in the southern California Bight. Bull Mar Sci 86:355-385

Cowen RK (2002) Larval dispersal and retention and consequences for population connectivity. In: Sale PF (ed) Coral reef fishes: dynamics and diversity in a complex ecosystem. Academic Press, San Diego, CA, p 149-170

Cowen RK, Castro L (1994) Relation of coral reef fish larval distributions to island scale circulation around Barbados, West Indies. Bull Mar Sci 54:228-244

Cowen RK, Sponaugle S (2009) Larval dispersal and marine population connectivity. Ann Rev Mar Sci 1:443-466

Cowen RK, Lwiza KMM, Sponaugle S, Paris C, Olson D (2000) Connectivity of marine populations: open or closed? Science 287:857-859

Cowen RK, Paris CB, Srinivasan A (2006) Scaling of connectivity in marine populations. Science 311:522-527

D'Alessandro EK, Sponaugle S (2011) Comparative predation rates on larval snappers (Lutjanidae) in oceanic, reef, and nearshore waters. J Exp Mar Biol Ecol 399: 182-187

$>$ D'Alessandro E, Sponaugle S, Lee T (2007) Patterns and processes of larval fish supply to the coral reefs of the upper Florida Keys. Mar Ecol Prog Ser 331:85-100

Doherty PJ (2002) Variable replenishment and the dynamics of reef fish populations. In: Sale PF (ed) Coral reef fishes: dynamics and diversity in a complex ecosystem. Academic Press, San Diego, CA, p 327-355

Figueira WF, Lyman SJ, Crowder LB, Rilov G (2008) Smallscale demographic variability of the bicolor damselfish, Stegastes partitus, in the Florida Keys. Environ Biol Fishes 81:297-311

Gallego A, North EW, Petitgas P (2007) Introduction: status and future of modelling physical-biological interactions during the early life of fishes. Mar Ecol Prog Ser 347: 121-126

> Gerlach G, Atema J, Kingsford MJ, Black KP, Miller-Sims V (2007) Smelling home can prevent dispersal of reef fish larvae. Proc Natl Acad Sci USA 104:858-863

Hitchcock GL, Lee TN, Ortner PB, Cummings S, Kelble C, Williams E (2005) Property fields in a Tortugas eddy in the southern Straits of Florida. Deep-Sea Res I: 2195-2213

> Hodur RM (1997) The Navy Research Laboratory's Coupled Ocean/Atmosphere Mesoscale Prediction System (COAMPS). Mon Weather Rev 125:1414-1430

Hodur RM, Hong X, Doyle JD, Pullen J, Cummings J, Martin P, Rennic MA (2002) The Coupled Ocean/Atmosphere Mesoscale Prediction System (COAMPS). Oceanography (Wash DC) 15:88-98

Huebert K, Sponaugle S (2009) Observed and simulated swimming trajectories of late-stage coral reef fish larvae off the Florida Keys. Aquat Biol 7:207-216

Jenkins GP, Black KP (1994) Temporal variability in settlement of a coastal fish (Sillaginodes punctata) determined by low-frequency hydrodynamics. Limnol Oceanogr 39: 1744-1754

> Jenkins GP, King D (2006) Variation in larval growth can predict the recruitment of a temperate, seagrass- 
associated fish. Oecologia 147:641-649

Kang H, Kourafalou VH, Paris CB (2008) Influence of Florida Current frontal eddies on circulation and fish recruitment around the Florida Keys Reef Tract. Proc 11th Inter Coral Reef Symp 15:475-478

Kingsford M, Finn M (1997) The influence of phase of the moon and physical processes on the input of presettlement fishes to coral reefs. J Fish Biol 51:176-205

Kingsford M, Leis JM, Shanks A, Lindeman K, Morgan S, Pineda J (2002) Sensory environments, larval abilities and local self-recruitment. Bull Mar Sci 70:309-340

Kourafalou VH, Kang H (in press) Florida Current meandering and evolution of cyclonic eddies along the Florida Keys reef tract: Are they inter-connected? J Geophys Res doi:10.1029/2011JC007383

Kourafalou VH, Peng G, Kang H, Hogan PJ, Smedstad OM, Weisberg RH (2009) Evaluation of Global Ocean Data Assimilation Experiment products on South Florida nested simulations with the Hybrid Coordinate Ocean Model. Ocean Dyn 59:47-66

Lemberget T, McCormick MI (2009) Replenishment success linked to fluctuating asymmetry in larval fish. Oecologia 159:83-93

Lemberget T, McCormick M, Wilson DT (2009) Environmental influences on the replenishment of lizardfish (family Synodontidae) in Caribbean Panama. Coral Reefs 28:737-750

Lee TN, Clarke ME, Williams E, Szmant AF, Berger T (1994) Evolution of the Tortugas Gyre and its influence on recruitment in the Florida Keys. Bull Mar Sci 54:621-646

Leis JM (2006) Are larvae of demersal fishes plankton or nekton? Adv Mar Biol 51:57-141

Lidz BH, Reich CD, Peterson RL, Shimm EA (2006) New maps, new information: coral reefs of the Florida Keys. J Coast Res 222:260-282

Limouzy-Paris CB, Graber HC, Jones DL, Roepke AW, Richards WJ (1997) Translocation of larval coral reef fishes via sub-mesoscale spin-off eddies from the Florida Current. Bull Mar Sci 60:966-983

> Lo-Yat A, Simpson SD, Meekan M, Lecchini DD, Martinez E, Galzin R (2011) Extreme climatic events reduce ocean productivity and larval supply in a tropical reef ecosystem. Glob Change Biol 17:1695-1702

Macpherson E, Raventos N (2005) Settlement patterns and post-settlement survival in two Mediterranean littoral fishes: influences of early-life traits and environmental variables. Mar Biol 148:167-177

Milicich MJ (1994) Dynamic coupling of reef fish replenishment and oceanographic processes. Mar Ecol Prog Ser 110:135-144

Mitarai S, Siegel DA, Winters KB (2008) A numerical study of stochastic larval settlement in the California Current system. J Mar Syst 69:295-309

North EW, Schlag Z, Hood RR, Li M, Zhong L, Gross T, Kennedy VS (2008) Vertical swimming behavior influences the dispersal of simulated oyster larvae in a coupled particle-tracking and hydrodynamic model of Chesapeake Bay. Mar Ecol Prog Ser 359:99-115

O'Connor MI, Bruno JF, Gaines SD, Halpern BS, Lester SE, Kinlan BP, Weiss JM (2007) Temperature control of larval dispersal and the implication for marine ecology, evolution and conservation. Proc Natl Acad Sci USA 104: 1266-1271

Paris CB (2009) Fate of reef fish larvae trough ontogeny: advection or true mortality? Theme Session T: death in the sea. Proceedings of the 2009 Annual Science Conference, September 21-25, 2009, Berlin, ICES CM 2009/T:13

Paris CB, Cowen RK (2004) Direct evidence of a biophysical retention mechanism for coral reef fish larvae. Limnol Oceanogr 49:1964-1979

Paris CB, Cowen RK, Lwiza KMM, Wang DP, Olson DB (2002) Objective analysis of three-dimensional circulation in the vicinity of Barbados, West Indies: implication for larval transport. Deep-Sea Res 49:1363-1386

Paris CB, Cowen RK, Claro R, Lindeman KC (2005) Larval transport pathways from Cuban snapper (Lutjanidae) spawning aggregations based on biophysical modeling. Mar Ecol Prog Ser 296:93-106

Paris CB, Chérubin LM, Cowen RK (2007) Surfing, spinning, or diving from reef to reef: effects on population connectivity? Mar Ecol Prog Ser 347:285-300

Purcell JFH, Cowen RK, Hughes C, Williams DA (2009) Population structure in a common Caribbean coral-reef fish: implications for larval dispersal and early life-history traits. J Fish Biol 74:403-417

Rankin T (2010) The effects of early life history on recruitment and early juvenile survival of a coral reef fish in the Florida Keys. PhD dissertation, University of Miami, Miami, FL

Richards WJ (2005) Early stages of Atlantic fishes. CRS Press, Boca Raton, FL

> Richardson DE, Llopiz JK, Cowen RK, Leaman KD, Vertes PS (2009) Sailfish (Istiophorus platypterus) spawning and larval environment in a Florida Current frontal eddy. Prog Oceanogr 82:252-264

Samhouri JF (2009) Food supply influences offspring provisioning but not density-dependent fecundity in a marine fish. Ecology 90:3478-3488

Schmitt RJ, Holbrook SJ (2002) Correlates of spatial variation in settlement of two tropical damselfishes. Mar Freshw Res 53:329-337

Shanks AL (2009) Barnacle settlement versus recruitment as indicators of larval delivery. II. Time-series analysis and hypothesized delivery mechanisms. Mar Ecol Prog Ser 385:217-226

Shenker JM, Maddox ED, Wishinski R, Pearl A, Thorrold SR, Smith N (1993) Onshore transport of settlementstage Nassau grouper Epinephelus striatus and other fishes in Exuma Sound, Bahamas. Mar Ecol Prog Ser 98: 31-43

> Siegel DA, Mitarai S, Costello CJ, Gaines SD, Kendall BE, Warner RR, Winters KB (2008) The stochastic nature of larval connectivity among nearshore marine populations. Proc Natl Acad Sci USA 105:8974-8979

> Simpson SD, Meekan M, Montgomery J, McCauley R, Jeffs A (2005) Homeward sound. Science 308:221

Sponaugle S, Cowen RK (1996) Nearshore patterns of coral reef fish larval supply to Barbados, West Indies. Mar Ecol Prog Ser 133:13-28

Sponaugle S, Lee T, Kourafalou V, Pinkard D (2005) Florida Current frontal eddies and the settlement of coral reef fishes. Limnol Oceanogr 50:1033-1048

Sponaugle S, Grorud-Colvert K, Pinkard D (2006) Temperature-mediated variation in early life history traits and recruitment success of the coral reef fish Thalassoma bifasciatum in the Florida Keys. Mar Ecol Prog Ser 308: $1-15$

Sweatman H (1988) Field evidence that settling coral-reef fish larvae detect resident fishes using dissolved chemical cues. J Exp Mar Biol Ecol 124:163-174 
Thorrold SR, Shenker JM, Maddox ED, Mojica R, Wishinski E (1994) Larval supply of shorefishes to nursery habitats around Lee Stocking Island, Bahamas. II. Lunar and oceanographic influences. Mar Biol 118:567-578

Tolimieri N, Haine O, Jeffs A, McCauley R, Montgomery J (2004) Directional orientation of pomacentrid larvae to ambient reef sound. Coral Reefs 23:184-191

- Watson JR, Mitarai S, Siegel DA, Caselle JE, Dong C, McWilliams JC (2010) Realized and potential larval con-

Editorial responsibility: Nicholas Tolimieri,

Seattle, Washington, USA nectivity in the Southern California Bight. Mar Ecol Prog Ser 401:31-48

- Werner FE, Cowen RK, Paris CB (2007) Coupled biological and physical models. Oceanography (Wash DC) 20: 54-69

Wilson DT, Meekan MG (2002) Growth-related advantages for survival to the point of replenishment in the coral reef fish Stegastes partitus (Pomacentridae). Mar Ecol Prog Ser 231:247-260

Submitted: October 17, 2011; Accepted: January 27, 2012 Proofs received from author(s): April 20, 2012 